\title{
К фауне чешуекрылых (Lepidoptera) в Белгородской области
}

\author{
А.Е. Годин \\ Специальная (коррекционная) общеобразовательная школа-интернат № 23, \\ Россия, 308036, г. Белгород, ул. Буденного, 4 \\ E-mail: shkola.internat23@yandex.ru u
}

\begin{abstract}
Аннотация. Приводятся данные о 8 видах чешуекрылых (Lepidoptera), впервые отмеченных на территории Белгородской области: Argynnis pandora (Denis et Schiffermüller, 1775), Calymma communimacula (Denis et Schiffermüller, 1775), Dysgonia algira (Linnaeus, 1767), Drasteria caucasica (Kolenati, 1846), Eutelia adulatrix (Hübner, 1813), Cucullia lactea (Fabricius, 1787), C. argentea (Hufnagel, 1766) и Noctua janthina Denis et Schiffermüller, 1775.
\end{abstract}

Ключевые слова: Nymphalidae, Erebidae, Euteliidae, Noctuidae, Центрально-Черноземный регион, новые находки.

Для цитирования: Годин А.Е. 2021. К фауне чешуекрылых (Lepidoptera) в Белгородской области. Полевой журнал биолога, 3 (1): 18-24. DOI: 10.52575/2658-3453-2021-3-1-18-24

Поступила в редакиию 22 января 2021 года

\section{To the Fauna of Lepidoptera in the Belgorod Region, Russia}

\author{
Alexander E. Godin \\ Special (correctional) secondary education Boarding-school № 23, \\ 4 Budyonnogo St, Belgorod, 308036, Russian Federation \\ E-mail: shkola.internat23@yandex.ru u
}

\begin{abstract}
Lepidoptera recorded for the first time in the Belgorod region: Argynnis pandora (Denis et Schiffermüller, 1775), Calymma communimacula (Denis et Schiffermüller, 1775), Dysgonia algira (Linnaeus, 1767), Drasteria caucasica (Kolenati, 1846), Eutelia adulatrix (Hübner, 1813), Cucullia lactea (Fabricius, 1787), C. argentea (Hufnagel, 1766) and Noctua janthina Denis et Schiffermüller, 1775. Specimens of butterflies were collected during the summer-autumn seasons of 2018-2020 using a light trap.
\end{abstract}

Keywords: Nymphalidae, Erebidae, Euteliidae, Noctuidae, Central Black Earth Region, new records.

For citation: Godin A.E. 2021. To the Fauna of Lepidoptera in the Belgorod Region, Russia. Field Biologist Journal, 3 (1): 18-24. (In Russian.) DOI: 10.52575/2658-3453-2021-3-1-18-24

Received January 22, 2021

\section{Введение}

Чешуекрылые насекомые на территория Белгородской области достаточно изучены. Результаты исследования отдельных групп Lepidoptera представлены в ряде работ [Кабанов, 1981; Присный, Седин, 1989; Присный, Гоголева, 1991; Стекольников, 1992; Свиридов, Тараненко, 2003; Стручаев, 2013]. В составе чешуекрылых Центрально- 
Черноземного региона (ЦЧР), по данным Каталога чешуекрылых России [2019], числится 964 вида, в том числе 253 подвида и 22 нуждающихся в уточнении. В Красную книгу Белгородской области занесены 35 видов бабочек [2019].

Несмотря на то, что фауна Lepidoptera Белгородской области исследуется уже почти полвека, некоторые виды, имеющие низкую численность или требующие специальных методов сбора, могут здесь быть отмечены дополнительно.

\section{Материал и методы исследования}

Сбор материала проводился в течение летне-осенних сезонов 2018-2020 гг. Дневные бабочки отлавливались с использованием энтомологического сачка, ночные бабочки - с использованием световой ловушки (дуговой ртутной люминофорной лампы мощностью 250 Вт и экрана) в следующих пунктах Белгородской области. Белгородский район: 1) окр. с. Репное, ур. Зеленая Яруга, опушка дубравы $(50,531576,36,510683)$; 2) окр. с. Болдыревка, ур. Муханово-Шеленково, опушка дубравы, берег пруда $(50,458963$, 36,428723); 3) окр. с. Варваровка, ур. Биопруд, берег пруда $(50,423444,36,409468)$. Шебекинский район: 4) окр. с. Архангельское, ур. Бор на мелу на трех холмах, левый берег p. Северский Донец, пойма $(50,356366,36,786621)$. Определение материала велось по специальным ключам [Определитель..., 1948; Ключко, 2006; Сочивко, Кабак, 2012]. Собранные бабочки смонтированы на булавки и хранятся в частной коллекции автора. Отличное состояние всех экземпляров подтверждает, что это не залетные особи с сопредельных территорий.

\section{Результаты исследования}

Среди собранных чешуекрылых были зарегистрированы 8 видов, ранее не отмечавшихся на территории Белгородской области. Далее приводится аннотированный список отмеченных видов с их краткой характеристикой.

Сем. Nymphalidae

1. Argynnis (Pandoriana) pandora (Denis et Schiffermüller, 1775) - Перламутровка пандора.

Материал: 4, 27.07.2020, 2 q и $3 \hat{\jmath}$ (рис. 1).
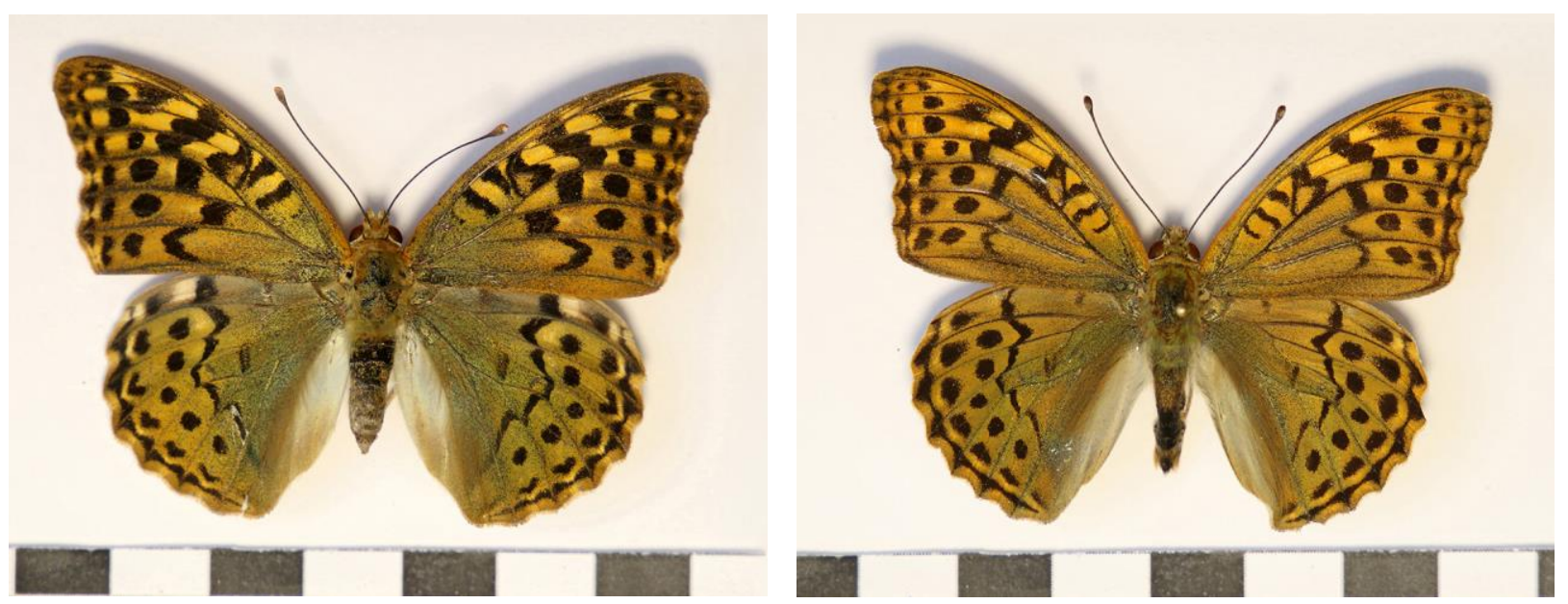

Рис. 1. Argynnis (Pandoriana) pandora (Denis et Schiffermüller, 1775) (слева - + , справа - §)), окр. с. Архангельское (Шебекинский р-н, Белгородская обл.), 2020 г. (шкала масштабной линейки - 1 см)

Fig. 1. Argynnis (Pandoriana) pandora (Denis et Schiffermüller, 1775) (left $-q$, right $-\widehat{O})$, vicinity of Arkhangelskoe village (Shebekinskiy district, Belgorod region), 2020 (scale $-1 \mathrm{~cm}$ ) 
Приурочен к местам произрастания кормового растения - фиалки лесной (Viola reichenbachiana Jord. ex Boreau, 1857).

Широко распространенный в Западной Палеарктике вид. Распространение: Украина, Крым, Центр европейской России [Fauna Europaea..., 2021]; известен из ВолгоДонского и Западно-Кавказского регионов, но для Центрального и ЦентральноЧерноземного регионов требуется подтверждение [Каталог..., 2019].

\section{Надсем. Noctuoidea Сем. Erebidae}

2. Calymma communimacula (Denis et Schiffermüller, 1775) - Калимма червецовая. Материал: 2, 18.08.2020, $1 \overbrace{}^{\Uparrow}$ (рис. 2A).

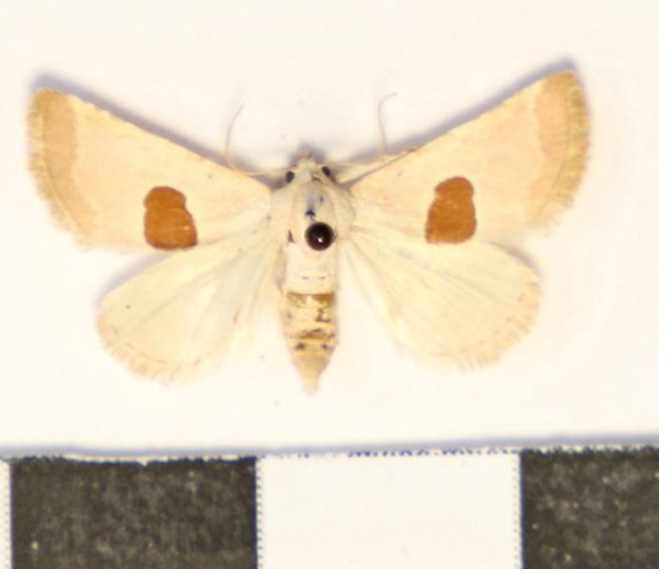

A

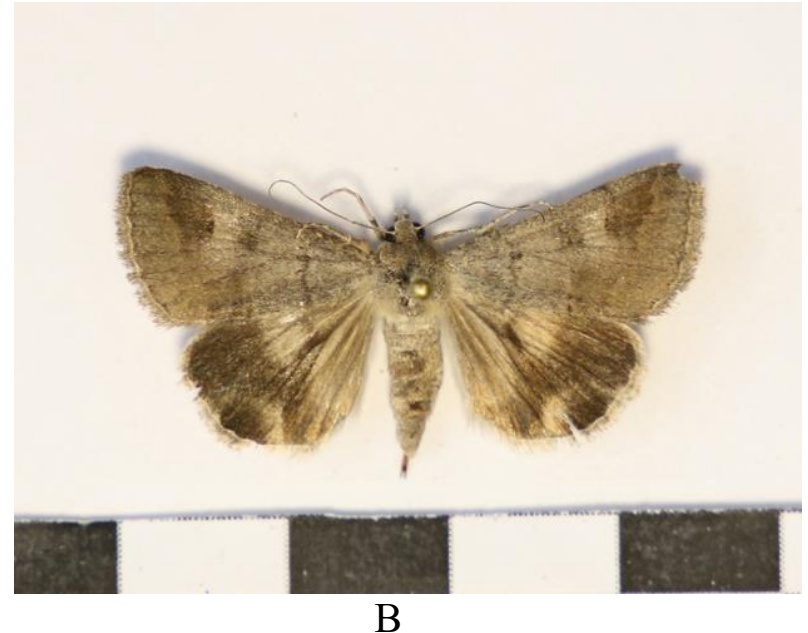

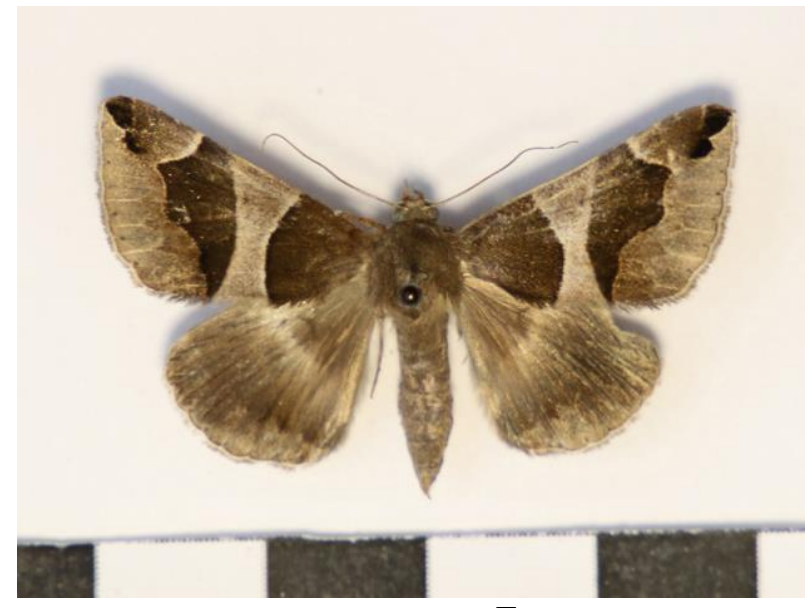

Б

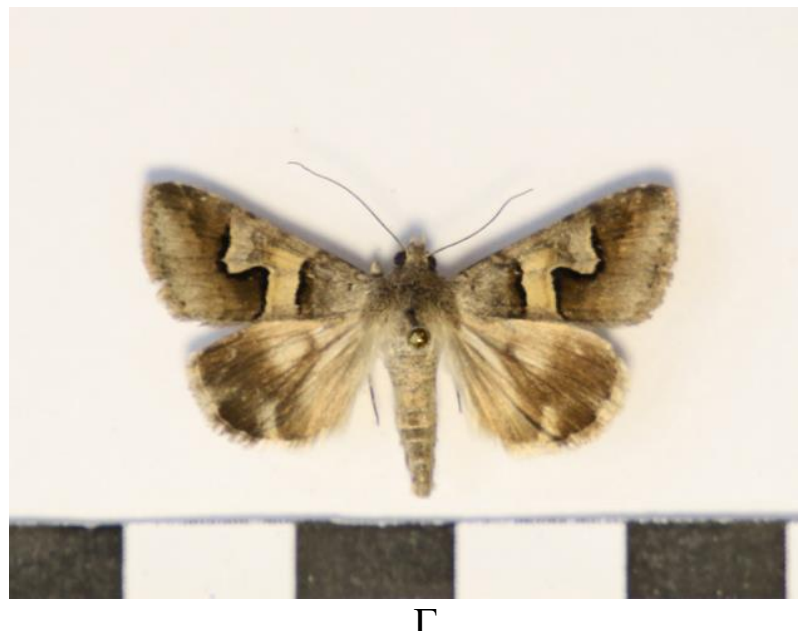

Рис. 2. Бабочки из сем. Erebidae, собранные на территории Белгородской области в 2020 г.:

A - Calymma communimacula (Denis et Schiffermüller, 1775), đે; Б - Dysgonia algira (Linnaeus, 1767),

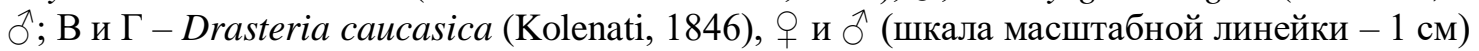

Fig. 2. Butterflies of Erebidae family, a specimens caught in Belgorod region in 2020:

A - Calymma communimacula (Denis et Schiffermüller, 1775), ô; Б - Dysgonia algira (Linnaeus, 1767),

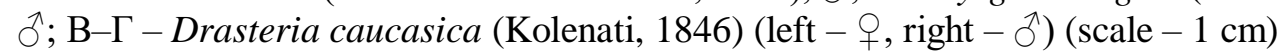

Гусеница питается личинками щетинистого мучнистого червеца Pseudococcus longispinus (Targioni Tozzetti, 1867), развивающегося на винограде.

Распространение: Украина, Крым, Юг европейской России [Fauna Europaea..., 2021]; известен из Волго-Донского, Кавказского и Крымского регионов [Каталог..., 2019]. 
3. Dysgonia algira (Linnaeus, 1767) - Совка расписная, или ленточница расписная.

Материал: 1, 15.08.2019, 1क; 2, 02.09.2020, 1ठ (см. рис. 2Б).

Считаю устойчивой популяцией, так как в личной коллекции находятся семь экземпляров, пойманных в Валуйском и Вейделевском районах. Питается малиной, ежевикой.

Распространение: Беларусь, Украина, Крым, Центр, Восток и Юг европейской России [Fauna Europaea..., 2021]; известен из Центрального, Волго-Донского, Кавказского и Крымского регионов [Каталог..., 2019].

4. Drasteria caucasica (Kolenati, 1846) - Совка-Драстерия кавказская.

Материал: 1, 27.07.2020, 1 и и 1ð; 4, 20.08.2018, 1ð (см. рис. 2В и 2Г).

Гусеницы питаются листьями лоха серебристого (Elaeagnus commutata Bernh. ех Rydb.) и облепихой (Hippophaё rhamnoides L.). Отмечалась в 1985 г. в Белгородской области в Валуйском (окр. с. Ново-Петровка) и Губкинском (окр. с. Вислая Дубрава) районах (в частной коллекции П.С. Козлова).

Распространение: Украина, Крым, Восток и Юг европейской России [Fauna Europaea..., 2021]; известен из Волго-Донского, Кавказского и Крымского регионов [Каталог..., 2019].

\section{Сем. Euteliidae}

5. Eutelia adulatrix (Hübner, 1813) - Эвтелия фисташковая.

Материал: 1, 17.08.2020, $1 \overbrace{}^{\Uparrow}$ (рис. 3 А).

Гусеница питается фисташковыми, а также сумахами (род Rhus L.), которые широко интродуцируются в нашем регионе (например, сумах оленерогий, или уксусное дерево (Rhus typhina L.)). Возможно дальнейшее увеличение численности эвтелии в местах произрастания сумахов.

Распространение: Украина, Крым, Юг европейской России [Fauna Europaea..., 2021]; известен из Волго-Донского, Кавказского и Крымского регионов [Каталог..., 2019].

\section{Сем. Noctuidae}

6. Cucullia (Cucullia) argentea (Hufnagel, 1766) - Капюшонница серебристая.

Материал: 1, 17.08.2020, 1ð̄ (рис. 3Б).

Кормовые растения - различные полыни (род Artemisia L.).

Распространение: Украина, Крым, Северо-Запад, Центр, Восток и Юг европейской России [Fauna Europaea..., 2021]; известен из Центрального, Средне-Волжского, ВолгоДонского и Кавказского регионов [Каталог..., 2019].

7. Cucullia (Cucullia) lactea (Fabricius, 1787) - Капюшонница молочно-белая.

Материал: 2, 19.11.2020, 1 и и 1ठ; 3, 13.07.2020, 2ð (см. рис. 3В-3Г).

Кормовые растения - различные полыни (род Artemisia L.).

Распространение: Украина, Крым, Восток и Юг европейской России [Fauna Europaea... 2021]; известен из Средне-Волжского, Волго-Донского, Кавказского и Крымского регионов [Каталог..., 2019].

8. Noctua janthina Denis\&Schiffermüller, 1775 - Совка ленточная тёмно-бурая.

Материал: 3, 7.07.2020, 5 экз., 12.07.2020, 3 экз.; 2, 20.08.2020, 4^ (см. рис. 3Д-3Е).

Гусеницы отмечены на первоцветах из рода Primula L., которые являются обычными растениями смешанных посадок и дубрав области.

В Центрально-Черноземном регионе приводится для Усманского бора Воронежской области [Кадастр беспозвоночных..., 2005].

Распространение: Беларусь, Украина, Крым, Юг европейской России [Fauna Europaea..., 2021]; известен из Волго-Донского, Кавказского и Крымского регионов [Каталог..., 2019]. 


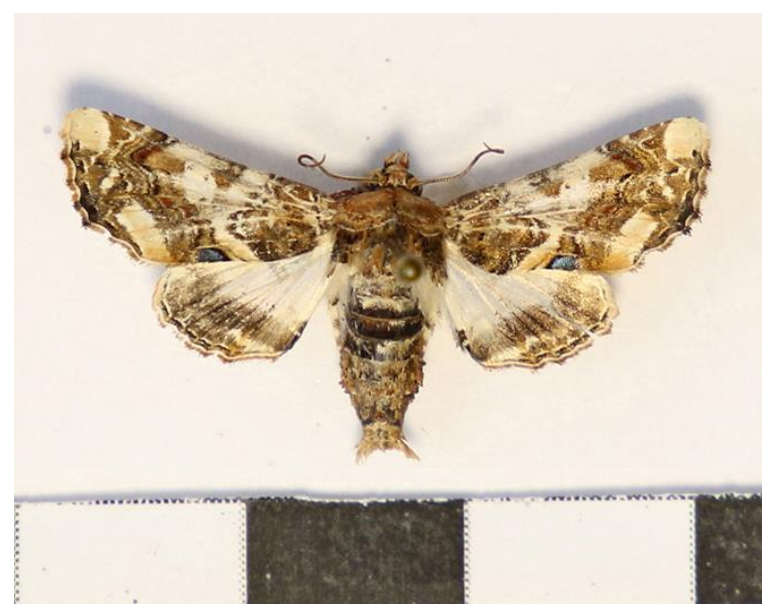

A
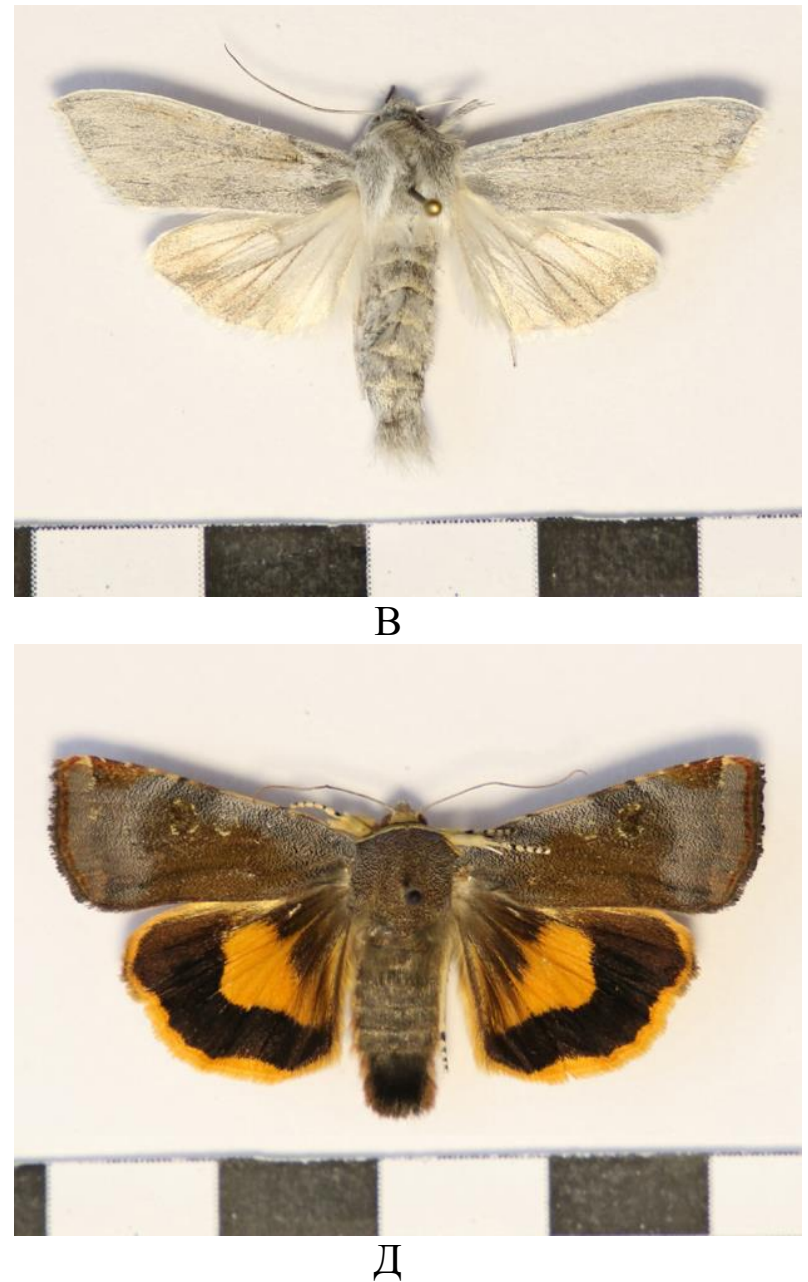

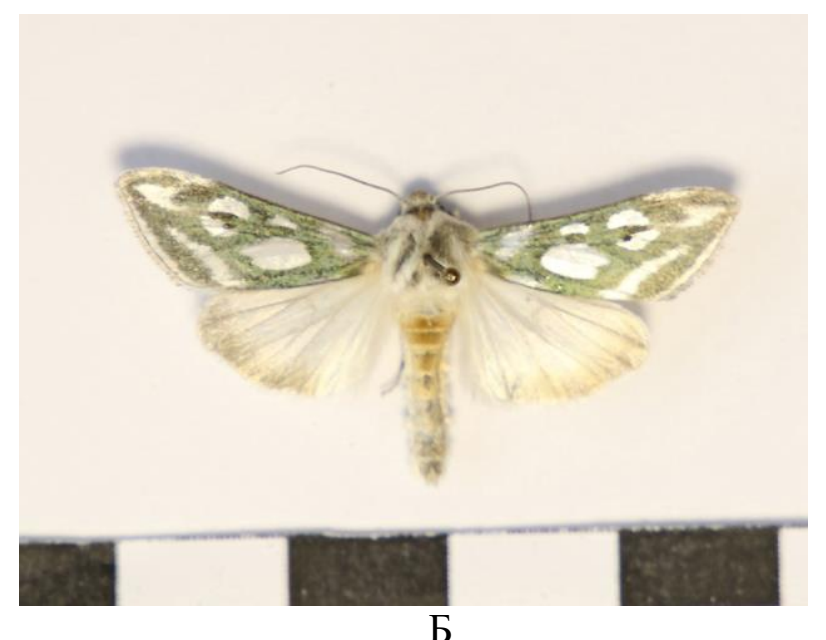

Б

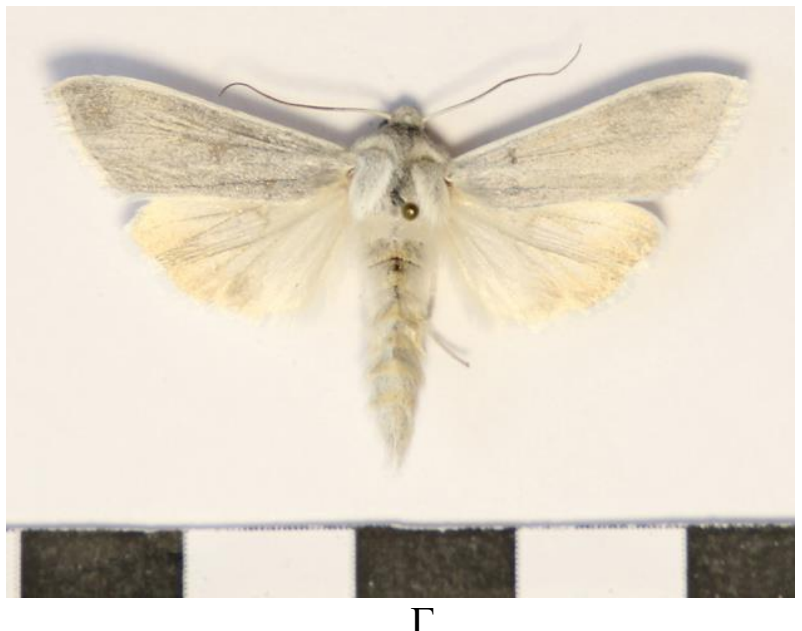

$\Gamma$

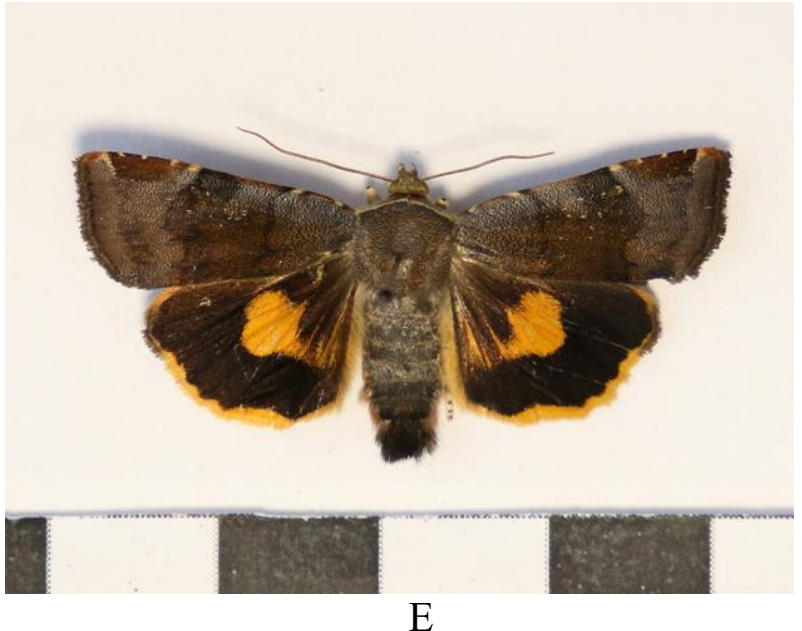

Рис. 3. Бабочки из сем. Euteliidae (А) и Noctuidae (Б-Е), собранные на территории Белгородской области в 2020 г.: А - Eutelia adulatrix (Hübner, 1813), О人; Б - Cucullia (Cucullia) argentea (Hufnagel,

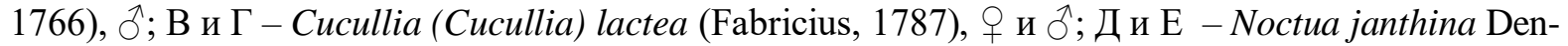
is\&Schiffermüller, 1775, ㅇ и $\widehat{~}$ (шкала масштабной линейки -1 см)

Fig. 4. Butterflies of Euteliidae and Noctuidae families, specimens caught in the Belgorod region

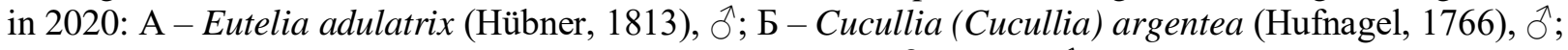

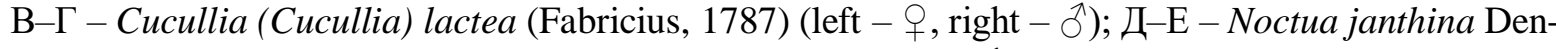
is\&Schiffermüller, 1775 (left $-\uparrow$, right $-\widehat{0})($ scale $-1 \mathrm{~cm})$ 


\section{Заключение}

Среди отмеченных 8 видов чешуекрылых обнаружение на территории Белгородской области A. pandora, L. morsei, D. algira, C. argentea и N. janthina было вполне ожидаемо, но требовалось подтверждение их мест обитания. E. adulatrix, предположительно, расширяет свой ареал в связи с интродукцией в регионе сумахов. Причины появления в регионе D. caucasica, C. communimacula и C. lactea требуют дополнительных исследований.

Стоит также отметить, что места сбора описанного материала расположены в непосредственной близости от населенных пунктов, где уже на протяжении 30 лет не проводилось весенних и осенних палов травы. Пожары, если возникали, то сразу гасились, то есть кормовая база и места окукливания бабочек практически не угнетались, что, вероятно, способствовало сохранению здесь отмеченных малочисленных видов.

\section{Список литературы}

1. Кабанов В.А. 1981. Зоогеографические особенности энтомофауны юга лесостепной зоны на примере Белгородской области. $B$ кн.: Научные труды Курского государственного педагогического института. Т. 210. Фауна и экология беспозвоночных лесостепной зоны. Сборник статей. Курск: 3-24.

2. Кадастр беспозвоночных животных Воронежской области. 2005. Воронеж, Воронежский государственный университет, 825 с.

3. Каталог чешуекрылых (Lepidoptera) России. 2019. Издание 2-е. Ред. С.Ю. Синёв. СанктПетербург, Зоологический институт РАН, 448 с.

4. Ключко 3. 2006. Совки Україны. Киев, Издательство Раевского, 248 с.

5. Красная книга Белгородской области. 2019. Редкие и исчезающие растения, лишайники, грибы и животные. 2-е официальное издание. Общ. науч. ред. Ю.А. Присный. Белгород, ИД «БелГУ» НИУ «БелГУ», 668 с.

6. Определитель насекомых Европейской части СССР. 1948. Ред. С.П. Тарбинский, Н.Н. Плавильщиков. М.-Л., Сельхозгиз, 1127 с.

7. Присный А.В., Гоголева Н.П. 1991. Животные Белгородской области, рекомендуемые к охране. Белгород, $105 \mathrm{c}$.

8. Присный А.В., Седин И.Ф. 1989. Некоторые итоги предварительного изучения энтомофауны Белгородской области. $B$ кн.: Всесоюзное совещание по проблеме кадастра и учета животного мира. Тезисы докладов. Ч. IV. Уфа, Башкирское книжное изд-во: 240-242.

9. Свиридов А.В., Татаренко Д.Е. 2003. Совки (Lepidoptera: Noctuidae) Курской и Белгородской областей. Russian Entomological Journal, 12 (4): 431-440.

10. Сочивко А.В., Кабак Л.В. 2012. Определитель бабочек России. Дневные бабочки. М., Мир энциклопедий Аванта+, Астрель, 320 с.

11. Стекольников А.А. 1992. Изменение фауны некоторых чешуекрылых (Lepidoptera: Hesperioidea, Papilionoidea, Sphingoidea etc) заповедной дубравы «Лес на Ворскле» за 50 лет наблюдений. Вестник Санкт-Петербургского университета. Серия 3. Биология, 2: 28-36

12. Стекольников А.А. 1993. Пяденицы (Lepidoptera, Geometridae) «Лес на Ворскле». Вестник Санкт-Петербургского университета. Серия 3. Биология, 1: 22-29.

13. Стручаев В.В. 2013. Скрытоживущие членистоногие-филлофаги деревьев и кустарников, интродуцированных на юге Среднерусской возвышенности. Дисс. ... канд. биол. наук. Белгород, 256 с.

14. Fauna Europaea: Lepidoptera. Available at: https://faunaeu.org/cdm_dataportal/taxon/b64a743d-0469-4571-9ed4-061779300ac0. (accessed 20 January 2021).

\section{References}

1. Kabanov V.A. 1981. Zoogeographic features of the entomofauna of the south of the foreststeppe zone on the example of the Belgorod region. In: Scientific works of the Kursk State Pedagogical Institute. T. 210. Fauna and ecology of invertebrates of the forest-steppe zone. Kursk: 3-24. (in Russian).

2. Cadastre of invertebrates of the Voronezh region. 2005. Voronezh, Voronezh State University, 825 p. (in Russian). 
3. Catalogue of the Lepidoptera of Russia. 2019. $2^{\text {nd }}$ edition. (Sinev S.Yu., ed.). St. Petersburg, Zoological Institute RAS, 448 p. (in Russian).

4. Klyuchko Z. 2006. Owlet Moths (Noctuidae) of Ukraine. Kiev, Raevsky Publishing House, 248 p. (in Russian).

5. Red Data Book of the Belgorod region. 2019. The plants, lichens, fungi and animals. $2^{\text {nd }}$ edition (Prisniy Yu.A., ed.). Belgorod, Publishing house "BelSU" NRU "BelSU", 668 p. (in Russian).

6. Determinant of the insects of the European part of the USSR. 1948. (Tarbinskiy S.P., Plavil'shchikov N.N., ed.). Moscow-Leningrad, Selkhozgiz, 1127 p. (in Russian).

7. Prisny A.V., Gogoleva N.P. 1991. Animals of the Belgorod region, recommended for protection. Belgorod, 105 p. (in Russian).

8. Prisny A.V., Sedin I.F. 1989. Some results of a preliminary study of the entomofauna of the Belgorod region. In: All-Union meeting on the problem of cadastre and accounting of the animal world. Part IV. Ufa, Bashkir Book Publishing House: 240-242. (in Russian).

9. Sviridov A.V., Tatarenko D.E. 2003. Noctuid Moths (Lepidoptera) of Kursk and Belgorod areas. Russian Entomological Journal, 12 (4): 431-440. (in Russian).

10. Sochivko A.V., Kabak L.V. 2012. Determinant of Butterflies of Russia. Daytime butterflies. Moscow, World of encyclopedias Avanta+, Astrel, 320 p. (in Russian).

11. Stekolnikov A.A. 1992. Changes in the fauna of some Lepidoptera (Lepidoptera: Hesperioidea, Papilionoidea, Sphingoidea etc) of the protected oak forest "Les na Vorskle" over 50 years of observations. Vestnik Sankt-Peterburgskogo universiteta. Seriya 3. Biologiya, 2: 28-36. (in Russian).

12. Stekolnikov A.A. 1993. Geometer Moths (Lepidoptera, Geometridae) of "Les na Vorskle". Vestnik Sankt-Peterburgskogo universiteta. Seriya 3. Biologiya, 1: 22-29. (in Russian).

13. Struchaev V.V. 2013. Hidden phyllophagous arthropods of trees and shrubs introduced in the south of the Central Russian Upland. Diss. ... cand. biol. sciences. Belgorod, 256 p.

14. Fauna Europaea: Lepidoptera. Available at: https://faunaeu.org/cdm_dataportal/taxon/b64a743d-0469-4571-9ed4-061779300ac0. (accessed 20 January 2021).

\section{ИНФОРМАЦИЯ ОБ АВТОРЕ}

Годин Александр Егорович, директор специальной (коррекционной) общеобразовательной школы-интерната № 23, г. Белгород, Россия

\section{INFORMATION ABOUT THE AUTHOR}

Godin Alexander E., Director of Special (correctional) secondary education Boarding-school No. 23, Belgorod, Russia 